\title{
Free thiomalate levels in patients with rheumatoid arthritis treated with disodium aurothiomalate: relationship to clinical outcome of therapy
}

\author{
S. R. RUDGE, ${ }^{1}$ D. PERRETT ${ }^{2}$ AND A. J. SWANNELL \\ From the ${ }^{I}$ Department of Rheumatology, City Hospital, Nottingham, and the ${ }^{2}$ Dunn Laboratories, St \\ Bartholomew's Hospital, London
}

SUMMARY Sixteen patients with seropositive rheumatoid arthritis were treated with $20 \mathrm{mg}$ disodium aurothiomalate (Myocrisin) weekly for six months. Disease activity was assessed before and after treatment. Plasma profiles and urinary excretion of free thiomalate were measured in all patients after the initial injection and again at six months in the 12 patients remaining on therapy. No difference was found in plasma levels or urinary excretion of free thiomalate between patients who responded to treatment or who developed toxic reactions and those who did not.

Disodium aurothiomalate has been used in the treatment of rheumatoid arthritis (RA) for more than 50 years but its mechanism of action remains unknown. It has recently been demonstrated that disodium aurothiomalate dissociates to form free thiomalate and protein-bound gold. ${ }^{1}$ While the absorption and excretion of the gold moiety have been extensively investigated, similar information on the thiol ligand is totally lacking. We have recently developed a method which allows quantitation of the low levels of free thiomalate found in physiological fluids during treatment with disodium aurothiomalate. ${ }^{2}$

The aim of this study was to determine whether plasma or urinary levels of free thiomalate, measured either after the initial injection or after prolonged therapy, correlated with either response to, or toxicity from, treatment with disodium aurothiomalate in patients with RA. The study was not designed to assess the value of gold salts in RA. Thus an untreated control group and a 'blind' observer were not indicated.

\section{Patients and methods}

Patients with definite or classical rheumatoid arthritis were admitted to the study if they failed to respond to simple analgesic or anti-inflammatory drugs. None had previously received gold or D-

Accepted for publication 20 February 1984.

Correspondence to Dr S. Rudge, Department of Rheumatology, City Hospital, Hucknall Road, Nottingham NG5 1PB. penicillamine, and none were currently receiving steroids. All participants gave informed consent to the study, which was approved by the Hospital Ethical Committee. Each patient was given an intramuscular test dose of $10 \mathrm{mg}$ disodium aurothiomalate (as Myocrisin) followed by weekly injections of $20 \mathrm{mg}$ for six months.

CLINICAL AND BIOCHEMICAL ASSESSMENTS A full clinical assessment was carried out on each patient on entry to the study by a single observer. Rheumatoid disease activity was assessed by the technique of multivariate analysis described by Mallya and Mace. ${ }^{3}$ Parameters measured were:

(1) duration of early morning stiffness (EMS) recorded in minutes; (2) pain score (PS), by a horizontal visual analogue scale; (3) grip strength (GS), measured with an aneroid manometer attached to a rubber cuff inflated to $40 \mathrm{mmHg}$; three readings were taken from each hand and the mean of all six recorded; (4) articular index (AI), by the method of Ritchie et al. $^{4}$; (5) haemoglobin (g/dl), by Coulter counter; (6) ESR (mm/h), by the Westergren method. Each parameter was divided into four arbitrary grades (Table 1).

Clinical and biochemical assessments were repeated at the end of six months by the same observer whether or not the patient was still receiving disodium aurothiomalate.

THIOMALATE PROFILES

Plasma and urinary profiles of free thiomalate were undertaken in all patients following their first $20 \mathrm{mg}$ 
Table 1 Grading of parameters for disease activity

\begin{tabular}{llllllc}
\hline Grade & $\begin{array}{l}\text { Early morning } \\
\text { stiffness } \\
(\text { min })\end{array}$ & $\begin{array}{l}\text { Pain } \\
\text { score }\end{array}$ & $\begin{array}{l}\text { Grip strength } \\
(\mathrm{mmHg})\end{array}$ & $\begin{array}{l}\text { Articular } \\
\text { index }\end{array}$ & $\begin{array}{l}\mathrm{Hb} \\
(\mathrm{g} / \mathrm{dl})\end{array}$ & $\begin{array}{l}\text { ESR } \\
(\mathrm{mm} / \mathrm{h})\end{array}$ \\
\hline 1 & 10 & $0-2$ & $>200$ & 0 & $>14 \cdot 1$ & $0-20$ \\
2 & $10-30$ & $3-4$ & $50-200$ & $1-7$ & $13-14$ & $21-45$ \\
3 & $31-120$ & $5-6$ & $21-49$ & $8-17$ & $10-12 \cdot 9$ & $46-80$ \\
4 & $>120$ & $7-10$ & $<20$ & $>18$ & $<9 \cdot 9$ & $>81$
\end{tabular}

Index of disease activity (IDA) is the sum of grades for each parameter, thus ranging from 1.0 to 4.0 (adapted from Mallya and Mace ${ }^{3}$ ).

dose of disodium aurothiomalate. Profiles were repeated after six months in all patients remaining on gold therapy; it was not considered ethical to rechallenge patients with disodium aurothiomalate if they suffered a toxic reaction.

Sampling procedure. After an overnight fast basal venous blood and urine samples were taken at $0900 \mathrm{~h}$. An intramuscular injection of $20 \mathrm{mg}$ disodium aurothiomalate was then given. Blood samples were obtained by separate forearm venepuncture at 15 , $30,45,60,90$, and 240 minutes. Samples were collected into tubes containing disodium ethylenediaminetetra-acetic acid (EDTA), final concentration $5 \mathrm{mmol} / \mathrm{l}$, and centrifuged for $5 \mathrm{~min}$. Plasma proteins were precipitated by the addition of $100 \mu \mathrm{l}$ of sulphosalicylic acid $(2 \mathrm{~mol} / \mathrm{l})$ to $1 \mathrm{ml}$ of plasma. After a further $5 \mathrm{~min}$ centrifugation the supernatant was removed, rapidly frozen in solid $\mathrm{CO}_{2}$. and stored at $-20^{\circ} \mathrm{C}$ until analysis. Urine samples for the periods between 0 and $1 \mathrm{~h}, 1$ and $2 \mathrm{~h}$, 2 and $4 \mathrm{~h}$, and 4 and $24 \mathrm{~h}$ were collected into $6 \mathrm{~mol} / \mathrm{l}$ $\mathrm{HCl}(1 \mathrm{ml}$ per $100 \mathrm{ml}$ of urine). Urine volumes were measured and aliquots were then frozen at $-20^{\circ} \mathrm{C}$ until analysis.

Free thiomalate assay. Concentrations of free thiomalate were measured by high-performance liquid chromatography and electrochemical detection as described previously. ${ }^{2}$
Statistics. Comparison of patient data before and after six months' treatment with disodium aurothiomalate was performed by Student's $t$ test for paired samples. The Mann-Whitney U test was used for analysis of plasma and urinary thiomalate data. The area under the plasma concentration versus time curves (AUC ${ }^{0-4 \mathrm{~h}}$ ) was calculated by the trapezoidal rule.

\section{Results}

Sixteen consecutive patients with RA (13 female, 3 male) took part in the study; no eligible patient declined to participate. Mean age was $51.8 \pm 11.6$ years, and mean disease duration was $2.9 \pm 1.8$ years. Twelve patients completed six months' therapy with disodium aurothiomalate. The mean total dosage was $593 \pm 134 \mathrm{mg}$ (range 300-775). Four patients discontinued therapy because of toxicity; three developed rashes and the fourth complained of intense generalised pruritus. Mean total dosage at discontinuation in the toxic group was $376 \pm$ $102 \mathrm{mg}$.

Clinical and biochemical assessments. These results are shown in Table 2. All parameters except $\mathrm{Hb}$ improved significantly over the six-month treatment period.

On the basis of the change in IDA patients were classified as 'responders' or 'non-responders'. A

Table 2 Clinical and biochemical assessments on entry and at six months in 16 patients

\begin{tabular}{lccl}
\hline Measurement & On entry & At 6 months & $\begin{array}{l}\text { Significance of } \\
\text { difference }(p<)\end{array}$ \\
\hline Early morning stiffness (min) & $118 \pm 76$ & $48 \pm 66$ & 0.002 \\
Pain score & $6 \pm 2$ & $3 \pm 2$ & 0.0001 \\
Grip strength (mmHg) & $102 \pm 63$ & $134 \pm 77$ & 0.003 \\
Articular index & $16 \pm 6$ & $7 \pm 4$ & $0 \cdot 001$ \\
Hb (g/dl) & $11 \cdot 5 \pm 1 \cdot 5$ & $11 \cdot 7 \pm 1 \cdot 0$ & $\mathrm{NS}$ \\
ESR (mm/h) & $54 \pm 20$ & $28 \pm 16$ & 0.001 \\
Index of disease activity & $2 \cdot 9 \pm 0 \cdot 5$ & $2 \cdot 1 \pm 0 \cdot 6$ & 0.001 \\
\hline
\end{tabular}

Results are presented as mean $\pm \mathrm{SD}$. 
700 Rudge, Perrett, Swannell

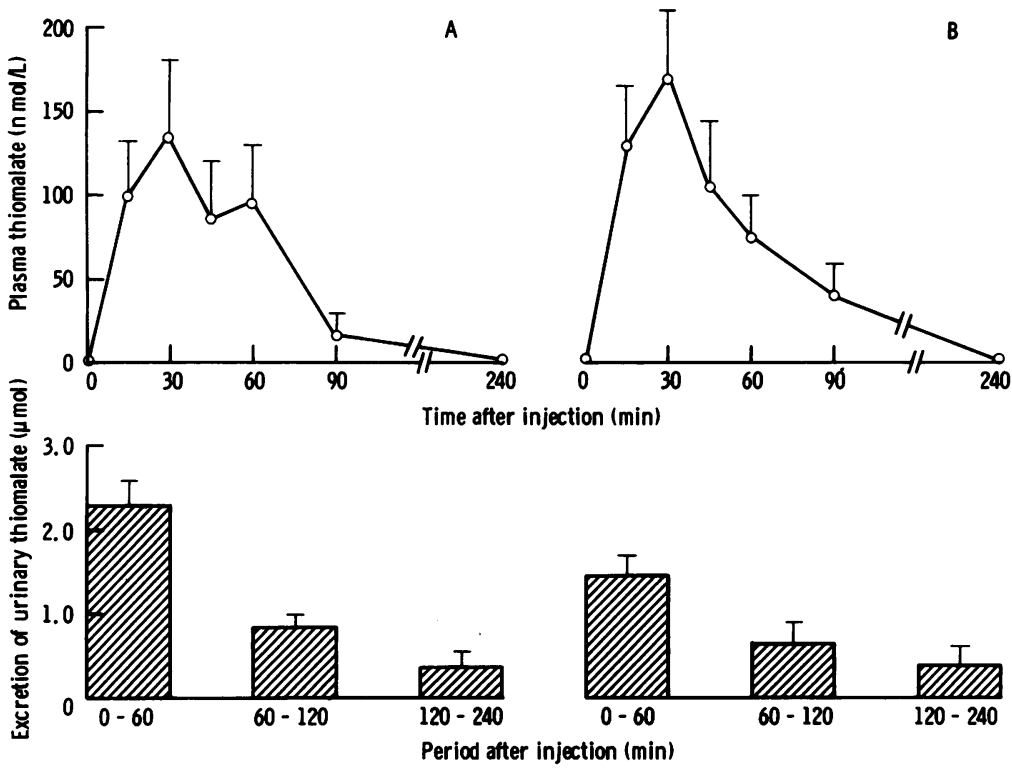

Fig. 1 Plasma concentrations and urinary excretion of free thiomalate during the first four hours after intramuscular injection of $20 \mathrm{mg}$ disodium aurothiomalate. A: Following the initial injection (16 patients). B: At six months (12 patients). Data are presented as mean $\pm S E M$.
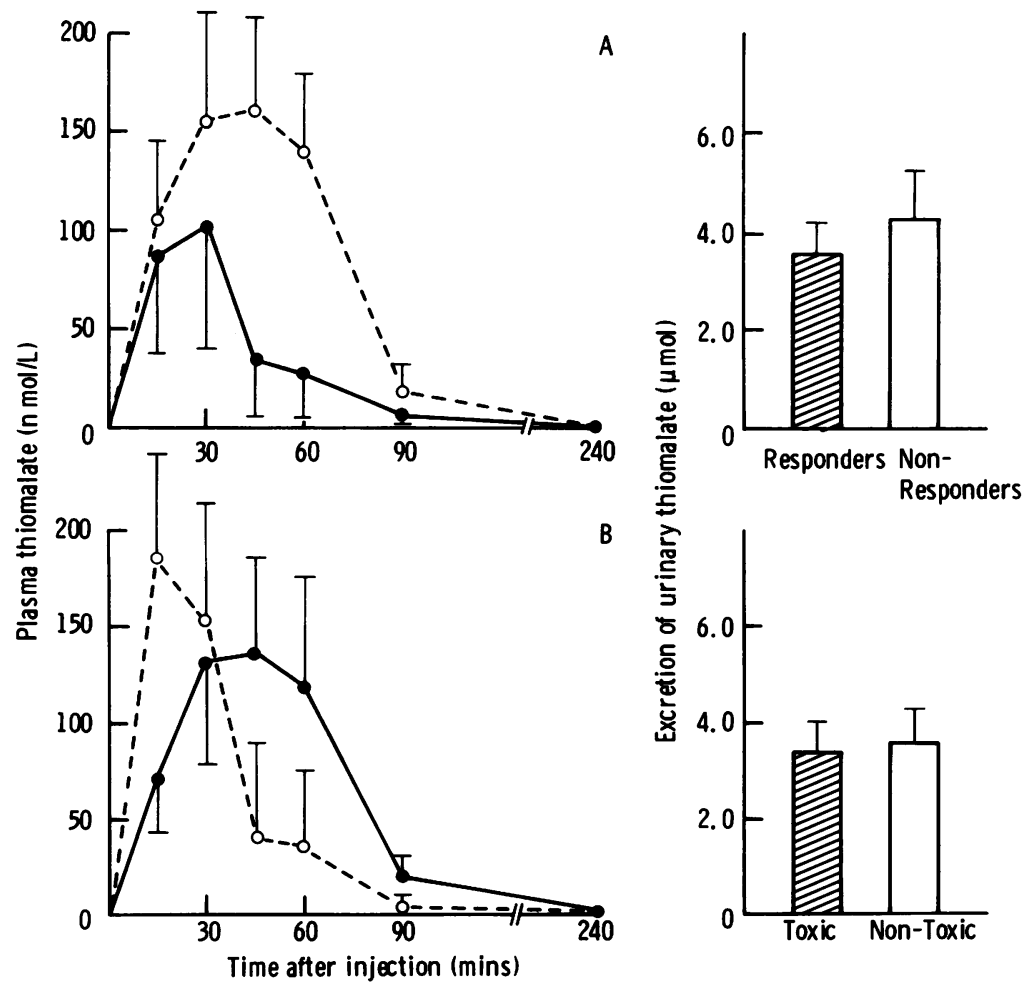

Fig. 2 Plasma concentrations and 24-hour urinary excretion of free thiomalate after the initial dose of disodium aurothiomalate in: A: Responders (O- - - ) and non-responders (O). B: Those who developed toxicity $\left(\mathrm{O}-\mathrm{O}_{-} \mathrm{O}\right)$ and those who did not (O). Data are presented as mean $\pm S E M$. 
change in IDA of greater than 0.5 was empirically taken to indicate response; 10 of the 16 patients showed such a response. Of the six patients who did not respond three had discontinued therapy because of toxic reactions.

Plasma and urinary free thiomalate levels. After the initial injection free thiomalate was detected in the plasma of 11 of 16 patients and at six months in the plasma of 10 of 12 patients. In only one patient was it not possible to detect free thiomalate on either occasion. Mean plasma free thiomalate levels are shown in Fig. 1.

Free thiomalate was detected in the urine of all patients. Mean levels for the $24 \mathrm{~h}$ following injection are shown in Fig. 1. On each occasion maximum excretion occurred during the first hour. The percentage of the total dose of aurothiomalate administered, excreted in the urine in $24 \mathrm{~h}$ as free thiomalate (expressed on a molar basis), ranged from 2.2 to $16.0 \%$ (mean $6.9 \pm 3.7 \%$ ) on entry and from 1.2 to $7.3 \%$ (mean $4.7 \pm 1.9 \%$ ) at six months.

Plasma levels of free thiomalate (measured as area under curve $0-4 \mathrm{~h}$ ) were not related to body weight. Plasma free thiomalate levels and $24 \mathrm{~h}$ urinary free thiomalate excretion, both on entry and at six months, did not differ significantly between 'responders' and 'non-responders' (Fig. 2). Similarly there was no difference in initial plasma and urinary free thiomalate levels between patients who subsequently developed toxic reactions and those who did not (Fig. 2). Although the mean peak plasma level was greater in patients who responded to treatment, this difference was not statistically significant.

\section{Discussion}

This study confirms, in a larger group of patients, that free thiomalate may be detected in the plasma and urine of patients with rheumatoid arthritis receiving disodium aurothiomalate. ${ }^{5}$

Until now clinicopharmacological studies of disodium aurothiomalate have dealt exclusively with the gold moiety. The majority have failed to establish any relationship between serum or urinary gold levels and clinical outcome of treatment. ${ }^{6-8}$ The present study fails to show any relationship between free thiomalate levels in plasma or urinary free thiomalate excretion and response to, or toxicity from, treatment with disodium aurothiomalate. The numbers of patients are small, however, and these results do not completely exclude the possibility that such a relationship exists. The observation that peak plasma thiomalate levels following the initial injection of disodium aurothiomalate tend to be higher in responders than non-responders, although not statistically significant, merits investigation in a larger number of patients.

However, it may be that the measureable free thiomalate does not represent the therapeutically active pool. Only a small proportion $(1-16 \%)$ of thiomalate is excreted in the free form, and it is likely that the majority of the thiomalate in plasma is strongly bound to plasma proteins, from where it might be released at metabolically active sites. The metabolites of thiomalate have not yet been determined, but by analogy with $\mathrm{D}$-penicillamine the major ones are likely to be thiomalate disulphide, cysteine-thiomalate disulphide, homocysteinethiomalate disulphide, and possibly an S-methyl form. ${ }^{9}$ These are not detected by our assay, which is specific for free-SH groups. Interestingly, Butler $e t$ al. ${ }^{10}$ have suggested from studies on D-penicillamine that disulphide metabolites of thiol-containing drugs may be more therapeutically active than the free form.

Further investigation of these questions awaits the application of assays capable of measuring both the free drug and its oxidised forms. Both those at present available for D-penicillamine ${ }^{11} 12$ include lengthy and complex reduction procedures which render them unsuitable for human studies. In addition, cellular rather than plasma levels of thiol-containing drugs may be more relevant to their pharmacological action in man.

Our thanks are due to Dr D. H. Bossingham for allowing us to study his paticnts and to Professor C. J. Dickinson for providing laboratory facilities. This study was supported by a project grant from the Arthritis and Rheumatism Council.

\section{References}

1 Rudge S R, Perrett D, Swannell A J, et al. Circulating thiomalate after administration of disodium aurothiomalate: impurity or active metabolite? J Rheumatol 1984; 11: 150-2.

2 Rudge S R, Perrett D, Drury P L, et al. The determination of thiomalate in physiological fluids by high-performance liquid chromatography and electrochemical detection. J Pharm Biomed Anal 1983; 1: 205-10.

3 Mallya R K, Mace B E. The assessment of disease activity in rhcumatoid arthritis using a multivariate analysis. Rheumatol Rehabil 1981; 20: 14-7.

4 Ritchic D M. Boyle J A. Mclnnes J M. et al. Clinical studies with an articular index for the assessment of joint tenderness in patients with rheumatoid arthritis. Am J Med 1968; 147: 393-406.

5 Rudge S R. Perrett D, Swannell A J. Free thiomalate in plasma and urine of paticnts recciving sodium aurothiomalate. Ann Rheum Dis 1984; 43: 66-9.

6 Mascarenhas B R, Granda J L, Freyberg R H. Gold metabolism in patients with rheumatoid arthritis treated with gold compounds-reinvestigated. Arthritis Rheum 1972; 15: 391402.

7 Gerber R C, Paulus H E. Bluestone R, et al. Clinical response and serum gold levels in chrysotherapy: lack of correlation. $A n n$ Rheum Dis 1972; 31: 308-10. 
8 Rubinstein H M, Dietz A A. Serum gold. II. Levels in rheumatoid arthritis. Ann Rheum Dis 1973; 32: 128-32.

9 Perrett D. The metabolism and pharmacology of Dpenicillamine in man. $J$ Rheumatol 1981; 8 (suppl 7): 41-50.

10 Butler M, Carruthers G, Harth M, et al. Pharmacokinetics of reduced $D$-penicillamine in patients with rheumatoid arthritis. Arthritis Rheum 1982; 25: 111-6.
11 Saetre R, Rabenstein D L. Determination of penicillamine in blood and urine by high performance liquid chromatography. Anal Chem 1978; 50: 276-80.

12 Abounassif $M$ A, Jefferies T M. The determination of D-penicillamine and its disulphide in plasma by reversed-phase ion-pair high performance liquid chromatography. $J$ Pharm Biomed Anal 1983; 1: 65-72. 